\title{
Contribution of International and Comparative Approach to the Policy and Practice of Teacher Education
}

\author{
Xinwei Bian* \\ Faculty of Social Science \& Public Policy, King's College London, London WC2R2LS, United Kingdom \\ *Corresponding author: Xinwei Bian, K1814423@kcl.ac.uk
}

\begin{abstract}
This study intends to identify the value and pitfalls of international and comparative approach for the policy and practice of teacher education. The structure of this article proceeds as follows: the first section focuses on explaining the meaning and the values of international and comparative approach; based on previous discussions, the second section makes a more in-depth analysis of the values of international and comparative approach to teacher education from five key themes; the final section of this article proposes and interprets the drawbacks of international and comparative approach in teacher education.
\end{abstract}

Keywords: International and comparative approach; International and comparative education; Teacher education; Policy and practice of teacher education

Publication date: November 2021; Online publication: November 30, 2021

\section{Introduction}

International and comparative education, with a long history, has encountered repeated challenges due to the constant change of times and professional agendas. Recently, international and comparative education has been creatively revitalized due to an enhanced research base, the increasing awareness of cross-cultural issues in teacher education, and the growing recognition of the significance of comparative approach. The purpose of comparative education studies is to identify differences that make the education of a country distinct from that of another and further explore differences in social, political, economic, and religious factors that contribute to the education system. Globalization, in particular, has become a significant force that shapes international and comparative education ${ }^{[1]}$. Globalization is considered as the widening, deepening, and speeding up of worldwide interconnectedness in all aspects of contemporary social life ${ }^{[2]}$. Globalization has significantly influenced the nature of the discourse of comparative education, such as using the analytical framework for intercountry comparison, the shift of the focus to cross-border international education, and the influence of globalization at the national level ${ }^{[3]}$. Correspondingly, international comparative study has become a prominent characteristic in education policymaking and its related process. The setup of international economic groups, geopolitical changes, improved international transportation, and the development of information technology have encouraged comparative education research, which is growingly used by policymakers with eagerness to identify innovative solutions from elsewhere for domestic problems.

This article critically discusses the contribution of international and comparative approach to the policy and practice of teacher education. Teacher education is a continuum of professional development for teachers for the purpose of improving their practice and promoting professional development ${ }^{[4]}$. Teachers 
are the most critical element in the educational system as they are the ones in charge of effectuating educational programs. Therefore, teacher education is essential to make sure that teachers are well and fully prepared as well as equipped with essential skills and abilities ${ }^{[5]}$.

\section{International and comparative approach}

Prior to discussing the values and pitfalls of international and comparative approach to the policy and practice of teacher education, it is first essential to identify what international and comparative approach is. Since the mid-20th century, international and comparative education has been taken as an academic field of study. No consensus has yet been reached regarding the definition. Generally, international and comparative education is taken as an amorphous field relying upon other disciplines like anthropology, sociology, political science, philosophy, economics, history, and psychology to meet the aim and objective

${ }^{[6]}$. This suggests that it is interdisciplinary in nature. There are confusion and misunderstandings among three concepts: international and comparative education, comparative and international education, as well as comparative education ${ }^{[1]}$. While Schweisfurth tried to define the concept of comparative and international education, it is unclear whether it is defining one field, comparative and international education, or two fields (i.e., comparative education and international education). It has been acknowledged that comparative studies tend to be frequently linked with the western industrialized world, but international education suggests the education study in all its form in developing countries ${ }^{[7]}$. Furthermore, it has been proposed that international education and comparative education are complementary, each of which is established upon the other ${ }^{[8]}$. Separately, comparative education is defined as a field applying historical, philosophical, and social science theories and approaches to international problems in education [9]. International education refers to the study of international schools, curricula, and concepts like global citizenship ${ }^{[10]}$.

Comparative and international education is a growing field of inquiry related to academic studies on wide-ranging educational issues and themes in different cultures, countries, and regions ${ }^{[11]}$. This suggests that the concept of international and comparative education is highly complicated and multidisciplinary in nature. In this article, international and comparative education is taken as two fields in which international education and comparative education are complementary and built upon each other. International and comparative education is about comparing similarities and differences of one's system with that of somewhere else and exploring the influence of practices and policies from somewhere else on one's own across the border.

\section{Why do people seek to make international comparisons in education?}

With the development of global communication, there has been a growing number of students crossing national borders for diverse education and educators traveling abroad for international collaborations. The public is also aware of educational systems except for their own, especially those of good reputations. Likewise, governments have been increasingly paying attention to international competitors and examples. For some policymakers, global markets and systems with quality guarantee are considered as well. The study on the correctness and accuracy of different educational systems is of practical significance for improvement and a better understanding of one's own educational system. Since the curricula of individual subjects in an educational system may become outdated and omit emerging approaches or topics of importance, the comparison and analysis of different curricula in several countries provide reference for the update of one country's curricula and stimulate scrutiny of its curricular design. In this way, relevant institutions or decision-makers can be informed of the differences between their curricula and those of other 
countries in terms of the curricular focus and contents in different subjects. These differences do not necessarily mean any fault as each country can be well justified in adopting curricula with variations according to the specific state of their educational system. Furthermore, international comparisons of educational achievements reveal significant differences in students' performance levels in different countries, thus providing information about factors that result in better educational achievements in certain countries compared to others. In general, these factors can be categorized into five types; namely, family background, school features, teacher characteristics, teaching practices and conditions, as well as student motivations. Based on the international analysis of the specific influence of these factors on different educational systems, both long-term and short-term improvements can be made to the educational systems in different countries.

Finally, although the international analysis and comparison of educational research involve various countries with a wide range of educational approaches and are more complicated than research in one county, this diversity requires the emphasis on more scientific methods for curricular analysis, more logical procedures for the measurement of educational outcomes, more comprehensive methodology for processing and analysis of large-size variables ${ }^{[12]}$. In this process, educational research can receive professional training sessions, which, in turn, provide them with the opportunity to practice and popularize these methods domestically. At the same time, they are more likely to closely follow the development of the latest research techniques. For research in specific subjects, such as mathematics, reading, and science, they can also benefit from more diverse perspectives involved in international studies as well as more detailed analyses of curricular development and teaching approaches in different countries. As a result, international comparison in education is of necessity in three significant aspects, including curricular design, educational system improvements, and educational research development. In the global era, this comparison has become a prominent approach and inevitable tendency that makes multi-faceted contributions from educational policymaking to educational practice.

\section{Values of international and comparative approach to teacher education}

Many scholars have made attempts to identify the benefits of comparative education studies. Noah has summarized the benefits of comparative education in terms of enriching the understanding of one's own education system, providing implications for policymakers and administrators, and offering insights for teacher education. Alternatively, comparative education enhances understanding of what the past is, what the present is, and what future to pursue ${ }^{[13]}$. Overall, international and comparative education can deepen the understanding in teacher education. It can assist policymakers and administrators. It allows a better understanding of the past, locating exactly of what the present is, and discern explicitly what the educational future should be like.

This section discusses five themed aspects. First, international and comparative approach allows teachers to learn from their reflections on their practice and that of others as well as nurture self-knowledge through comparing with others. To be more specific, compared with a study in a single context, international and comparative approach can promote teachers' self-knowledge and self-awareness, which are essential for promoting teachers' professional development ${ }^{[14]}$. For instance, the strategies used by teachers for disciplining students due to misbehaviors may vary across different countries or share certain similarities.

Patterns of using different classroom discipline strategies may be relatively identical in Australia and Israel, where teachers tend to respond to students' misbehaviors by communicating with them the problem and expressing their expectations for improvement. Besides, teachers may punish students who misbehaved and discuss with them the influence of their misbehaviors, so that students would be able to determine how to behave in the future. However, compared with teachers in Australia and Israel, Chinese teachers tend to adopt a different pattern. Chinese teachers do not use much aggression and punishment but depend more 
on rewards, involvement in decision-making, hinting, and discussions ${ }^{[15]}$.

Chinese teachers are likely to use words or hints to correct students' misbehaviors. These differences can be explained in part by cultural differences in these three countries. To be specific, Chinese teachers are traditionally respected in the classroom; thus, they seldom resort to punishment. The evidence presented thus far suggests that teachers in practice may be confronted with cultural difficulties when using an approach from another country. This offers some insights into the power relationships existing in schools and evidences the potential of using a comparative study for learning from the reflection on teachers' practice and others. It is dangerous to transfer the practice of teachers in an indiscriminate way ${ }^{[16]}$. For example, if the pattern of building relationships used among Chinese teachers is mirrored by other countries, the significance of students' respect and parents' supports for teachers' authority in classrooms should be recognized. Changes are needed in an incremental way to be in line with the capacity of the local context. Overall, it can be argued that international and comparative approach could help teachers optimize classroom practices according to the specific cultural context of each country.

Second, international and comparative approach allows policymakers and administrators to gain a better understanding of one's own education system and that of elsewhere. On the one hand, international and comparative approach can fulfill policymakers' and administrators' theoretical and practical curiosity about the education system that is practiced somewhere else and provide opportunities for learning something new about education. Some international comparative studies provide a more in-depth insight into the learning styles of student teachers and those of different countries. According to a questionnaire about the learning styles and methods preferred by pre-service teachers from China and the United States (US), there were significant differences between Chinese and American student teachers in their learning [17]. These confirm the importance of international comparison, which provides information about the teacher education system in other places to facilitate the learning of researchers and policymakers. On the other hand, it offers opportunities for improving the science, art, and craft of teaching, learning, as well as teacher education. Moreover, international and comparative approach allows one to gain a better understanding of his or her own education system through comparison with others ${ }^{[18]}$. This would result in the creation of a much more complicated picture of education if different sources are deployed. This offers a distinct opportunity for questioning one's own educational system as well as the taken-for-granted theoretical and practical perspectives ${ }^{[1]}$. The comparative approach offers a perspective for identifying similarities and differences between educational systems, which in turn contributes to theoretical and practical improvements. This is helpful in broadening the picture of educational issues by questioning the prevailing theory and proposing new approaches to investigating and facilitating the creation of new theories. What is much more pragmatic is that an international and comparative study allows administrators to identify what can be learned or borrowed from elsewhere. An international and comparative study allows teachers, policymakers, and administrators to understand one's own and others' educational system as well as reform their own educational system ${ }^{[12]}$. Therefore, based on the above discussion, international and comparative approach helps policymakers and researchers achieve an in-depth understanding of one's own educational system and that of elsewhere in order to put forward effective policies and practices for teacher education, which are applicable to their own culture.

Third, international and comparative approach can enrich understanding of the relationship between education, society, and context. By collecting data from different contexts, researchers are capable of identifying the cultural sources influencing teaching and teacher education ${ }^{[1]}$, so as to provide implications for policymaking and the administration of teacher education. There is evidence showing that the policymaking of teacher education varies with ideologies. For instance, in England, the English model is a paradigm directing teacher education. The English model is featured by the state's strongly controlling teacher education for creating a standardized and standard-based system ${ }^{[19]}$. However, Manitoba has 
adopted an institutional model, in which the government takes less direct control despite that the local government is actively setting up parameters for the teacher education program. Instead, individual institutions have the responsibility for determining the content. An alternative is a professional model based on negotiation between teacher education providers and the state. The differences are caused by different ideologies; to be specific, the notion of teachers' work as well as the nature of the teaching profession. This suggests the value of comparative study in clarifying how educational policies and practices can be constructed in a variety of national contexts. The models and policymaking in teacher education stand for different political cultures. Therefore, based on the above discussion, it can be suggested that international and comparative approach stimulates the consideration of different cultural or national contexts in the process of policymaking in teacher education.

Fourthly, international and comparative studies can enhance the understanding of international educational processes as they offer broad and nuanced data on the influence of globalization on various educational contexts ${ }^{[20]}$. In the context of globalization, there are diverging views. While some advocate global uniformity, others suggest maintaining local diversity. In the context of teacher education, international and comparative approach can initiate and make a contribution to the re-examination of educational goals. International and comparative studies are helpful in identifying intercultural and crosscultural binding as well as criticizing the international transfer of theories, policies, and practices. The aim of comparative education is to establish systematic studies on common issues, needs, and practices in different cultural contexts, so as to strengthen awareness of possibilities and clarify contextual constraints ${ }^{[18]}$. For instance, several cross-cultural studies of approaches to mistake management in mathematics classes have demonstrated that cultural factors influence the means of mistake management across different countries but without any great differences in the mistakes themselves ${ }^{[21]}$. It reminds the policymakers and teachers that culture is multilayered, and it is necessary to consider local context as well as individual differences. In view of all that has been mentioned in this section, it can be asserted that international and comparative approach provides researchers and policymakers with clues to complement the understanding of international educational processes and reconsider the international transfer of policies and practices in teacher education.

Fifth, from an intellectual perspective, international and comparative approach can provide yardsticks for making the judgment of performance in teacher education ${ }^{[8]}$. The capability of developing an approach to making the comparison is an indispensable aspect of intellectual inquiry, which is essential for decisionmaking in teacher education. This approach can describe different forms of education on a global scope, determine relationship and interaction among different dimensions of education, as well as define essential conditions needed for changes in teacher education. It can offer different yardsticks for judging the performance of the teacher education system and make a prediction of potential outcomes of specific actions by referring to the experience of other countries.

Overall, based on the analysis above, international and comparative education can be taken as a field involving the use of tools and perspectives from other areas with a focus on teacher education issues in a comparative context. This confirms that international and comparative approach is multidisciplinary in nature. The value of comparative education lies in enriching and deepening the understanding of one's own education system and context as well as assisting policymakers and administrators ${ }^{[13]}$. The approach allows identifying, explaining, evaluating, critiquing, and developing practices and policies for teacher education. It enhances awareness of cultural differences and encourages thinking about to what extent a policy or practice can be transferred from one context to another without adaptation.

\section{Pitfalls of international and comparative approach to teacher education}

Despite that international and comparative approach contributes to policies and practices of teacher 
education in many aspects, the approach has its limitations in conceptualization, data, access, and other aspects. First, the challenge is related to the conceptualization of international and comparative education. Despite that the studies on international and comparative education can be traced back to the 20th century, confusion and misunderstandings of international and comparative education remain ${ }^{[1]}$. For instance, Philips and Schweisfurth are ambiguous about whether international and comparative education is considered as two fields or one ${ }^{[8]}$. Alternatively, Schweisfurth contends that international education and comparative education are two fields that are complementary, whereas Fossum completely disregarded international education as a field. This indicates that the concept of international and comparative education has variation ${ }^{[8,22]}$. Drawing implications from international and comparative education for policy and practice design in teacher education, ambiguities and misconceptions of the concept undermine the value of international and comparative education ${ }^{[1]}$.

Second, the limitation of international and comparative education is related to contextualization. International and comparative education has been criticized for taking education as something that makes sense to discuss in different countries like China, the United Kingdom (UK), and Japan at all levels of the teacher education system with standardized terms and metrics. A possible consequence of the view is standardizing collected data. In teacher education context, many unquestioned assumptions have emerged, such as "teachers must improve to improve education," "teaching should be interpreted via shared lens," and "there are shared measurement for teachers' performance" ${ }^{[23]}$. Educational studies are also trapped by ethnocentrism, suggesting the preeminence of a single teacher education model or the superiority of practices or policies elsewhere. Historically, the aim of comparative study is to identify and explain differences, but recently, the great emphasis has been on policy transfer while cultural and institutional differences have been neglected.

Third, the limitation of international and comparative education is related to data. It is difficult to have access to official statistics data, which is considered as valuable and credible for international and comparative studies. At present, most comparative studies focus on collecting data through questionnaires or interviews. This means that a self-reported approach is being adopted. The data may be unreliable as the participants may intentionally hide their true feelings or thoughts. However, on the other hand, it is difficult to gain access to data. Moreover, statistical comparison may lack reliability across different countries.

Forth, the potential limitation of international and comparative education occurs when the context is not specially addressed or when the process of contextualization results in normless relativism. This suggests that the conclusion of international and comparative education would lack scientific validity. Nevertheless, a thorough contextualization in comparative education may reduce the possibility of uncritically transferring policies and practices. This suggests the importance of identifying "what to compare." At present, many education scholars have interest in concepts such as accountability, effectivity, and outcomes. There is a risk for comparative education researchers to be pawns. In order to protect against the risk, it is essential to emphasize on contextualization and ensure the studies focus on wide-ranging issues instead of merely hot topics expected by politics or policymakers. It is important to continually ponder about the purpose of comparative studies in teacher education. Instead of accommodating to achieve similar outcomes, it is much more important to know and understand the other party ${ }^{[24]}$.

Fifth, international and comparative approach may involve a tension between academics and policymakers. To be specific, academics may suspect the ways policymakers take advantage of comparative education for the sake of their own interest. They are concerned that ideology may excessively govern policymakers. This is manifested in comparative studies on systems, such as Program for International Student Assessment (PISA) and Trends in International Mathematics and Science Study (TIMSS), which result in distortion in the establishment of international "league tables" that oversimplify or completely disregard the contingencies or contextual factors ${ }^{[25]}$. On the other hand, policymakers tend to attack 
academics for their failure to generate practical solutions to specific teacher education issues. This suggests a boundary between academics' outcomes of comparative study and the needs of policymakers.

\section{Conclusion}

In conclusion, the purpose of this article is to discuss about the contribution of international and comparative approach to the policy and practice of teacher education as well as its limitations. The most prominent finding from this article is that international and comparative approach has many benefits for teacher education. To be specific, it has been found that international and comparative approach allows teachers to learn from their reflections on their own practice and that of others as well as to nurture selfknowledge; it helps policymakers and administrators gain a better understanding of one's education system and that of somewhere else; it enhances the understanding of the relationship among education, society, and context; it enriches the understanding of international educational processes as it offers broad and nuanced data on the influence of globalization on various educational contexts; it also provides yardsticks for making judgment on performance in teacher education. However, this article has also shown the limitations of international and comparative approach in teacher education. It highlights that the challenge of international and comparative approach is relevant to the conceptualization of international and comparative education, contextualization, data, failure of specializing context, and tension between academics and policymakers. Nevertheless, in spite of challenges or limitations, international and comparative approach should be used for teacher education. In other words, teacher education research should be engaged in international and comparative studies. A limitation of this article is that the number of literatures compared is relatively small, but it offers valuable insights into the role and limitations of international and comparative approach for the policy and practice of teacher education.

\section{Disclosure statement}

The author declares that there is no conflict of interest.

\section{References}

[1] Crossley M, Watson K, 2003, Comparative and International Research in Education: Globalisation, Context and Difference, Routledge Falmer, London and New York.

[2] Held D, McGrew A, Goldblatt D, et al., 1999, Global Transformations: Politics, Economics and Culture, Stanford University Press, Stanford.

[3] Bray M, 2003, Comparative Education in the Era of Globalisation: Evolution, Missions and Roles. Policy Futures in Education, 1(2): 209-224.

[4] Elliott J, (eds) 2011, Reconstructing Teacher Education (Vol. 221), Routledge.

[5] Darling-Hammond L, 2000, How Teacher Education Matters. Journal of Teacher Education, 51(3): 166-173.

[6] Kubow PK, Fossum PR, 2007, Comparative Education: Exploring Issues in International Context, Prentice Hall.

[7] Schweisfurth M, 2014, Among the Comparativists: Ethnographic Observations. Comparative Education, 50(1): 102-111.

[8] Philips D, Schweisfurth M, 2014, Comparative and International Education: An Introduction to Theory, Method, and Practice, Bloomsbury, New York. 
[9] Epstein EH, 2016, Why Comparative and International Education? Reflections on the Conflation of Names, Teaching Comparative Education: Trends and Issues Informing Practice, 57-73.

[10] Wilson DN, 2003, The Future of Comparative and International Education in a Globalised World, in Comparative Education, Springer, Dordrecht, 15-33.

[11] Bray M, 2007, International and Comparative Education: Boundaries, Ambiguities and Synergies, The SAGE Handbook of Research in International Education, 51-56.

[12] Fairbrother GP, 2005, Comparison to What End? Maximizing the Potential of Comparative Education Research. Comparative Education, 41(1): 5-24.

[13] Noah HJ, 1984, The Use and Abuse of Comparative Education. Comparative Education Review, 28(4): 550-562.

[14] Morris P, Williamson J, 2013, Teacher Education in the Asia-Pacific Region: A Comparative Study, Routledge.

[15] Lewis R, Romi S, Qui X, et al., 2005, Teachers' Classroom Discipline and Student Misbehavior in Australia, China and Israel. Teaching and Teacher Education, 21(6): 729-741.

[16] Ding M, Li Y, Li X, et al., 2008, Chinese Teachers' Perceptions of Students' Classroom Misbehaviour. Educational Psychology, 28(3): 305-324.

[17] You Z, Jia F, 2008, Do They Learn Differently? An Investigation of the Pre-Service Teachers from the US and China. Teaching and Teacher Education, 24(4): 836-845.

[18] Broadfoot P, 2000, Comparative Education for the 21st Century: Retrospect and Prospect. Comparative Education, 36(3): 357-371.

[19] Young J, Hall C, Clarke T, 2007, Challenges to University Autonomy in Initial Teacher Education Programmes: The Cases of England, Manitoba and British Columbia. Teaching and Teacher Education, 23(1): 81-93.

[20] Arnove RF, 2003, Introduction: Reframing Comparative Education: The Dialectic of the Global and the Local. Comparative Education: The Dialectic of the Global and the Local, 2: 1-23.

[21] Heinze A, Reiss K, 2007, Proceedings of the 31st Conference of the International Group for the Psychology of Mathematics Education, July 8-13, 2007: Mistake-Handling Activities in the Mathematics Classroom: Effects of an In-Service Teacher Training on Students' Performance in Geometry, The Korea Society of Educational Studies in Mathematics The Republic of Korea, 9-16.

[22] Kubow PK, Fossum PR, 2007, Comparative Education: Exploring Issues in International Context, Prentice Hall.

[23] Darling-Hammond L, 2010, Teaching and Educational Transformation, in Second International Handbook of Educational Change, Springer, Dordrecht, 505-520.

[24] Nóvoa A, Yariv-Mashal T, 2014, A Mode of Governance or a Historical Journey? World Yearbook of Education 2014: Governing Knowledge: Comparison, Knowledge-Based Technologies and Expertise in the Regulation of Education.

[25] Owens TL, 2013, Thinking Beyond League Tables: A Review of Key PISA Research Questions. PISA, Power and Policy: The Emergence of Global Educational Governance. Oxford Studies in Comparative Education, 23(1). 